\title{
SEISMIC HAZARD ESTIMATES FOR THE AUCKLAND AREA, AND THEIR DESIGN AND CONSTRUCTION IMPLICATIONS
}

\author{
David J. Dowrick1 \\ This is a revised version of a paper given at the Pacific Conference on \\ Earthquake Engineering, Auckland, November 1991
}

\begin{abstract}
SUMMARY
Revised estimates of the return periods of Modified Mercalli (MM) intensity for Auckland and Northland, arising from a revision of the attenuation of intensity in New Zealand, and latest data and views on the local seismicity and geology, represent considerable reductions in the hazard given in Smith and Berryman's seismic hazard model of New Zealand. The revised levels are MM6 and MM7 for 150 and 1200 year return periods. This implies that most structures and plant in Auckland and Northland could have much simpler and less onerous earthquake resistant design and construction than required by current codes. This simpler approach would be significantly cheaper for older so-called "earthquake risk buildings" as well as new construction.
\end{abstract}

\section{INTRODUCTION}

The seismicity of Auckland and Northland was first discussed in 1955 by Eiby [12], while more recently the seismic hazard of this area has been evaluated as part of New Zealand-wide studies, particularly those of Smith [23] and Smith and Berryman [24] who described the seismicity and geology and then estimated hazards in terms of frequency of occurrence of various levels of Modified Mercalli (MM) intensity. Using the New Zealand seismicity model [24], the New Zealand Seismic Risk Committee estimated seismic hazard in terms of frequency of spectral accelerations [17]. On the basis of the latter study the draft revision of the earthquake loadings code [28] set loadings levels which vary regionally in a more graduated manner than given by the current simple seismic zoning scheme [27] first introduced in 1965 [25] without the benefit of the above studies.

Hazard assessment is a function of attenuation of earthquake waves, and for intensity the attenuation expressions mostly used to date have been those proposed in the 1970's by Smith [22]. Recently intensity attenuation in New Zealand has been the subject of a major revision $[10,11]$ which creates the opportunity for revising the hazard estimates in terms of intensity for New Zealand generally, with the Auckland area being the subject of this paper.

\section{SEISMIC HAZARD IN AUCKLAND AND NORTHLAND}

Auckland and Northland are located in the least seismically active part of the country. As shown in Figure 1 this regions is the furtherest part of New Zealand from the Pacific-Australia

\footnotetext{
${ }^{1}$ DSIR Physical Sciences, Lower Hutt (Fellow).
}

tectonic plate boundary and the main belt of seismic activity accompanying it. The interplate zone is capable of generating the largest shallow earthquakes likely to occur in New Zealand (up to $M \approx 8.5$ ). The segment of this source of very large earthquakes that is closest to Auckland and Northland is located in Region D on Figure 2, at a distance of $300 \mathrm{~km}$ from Auckland City. As the subducting plate dips below the crust it gets as close as about $240 \mathrm{~km}$ from Auckland (at a depth of about $100 \mathrm{~km}$ below Region C in Figure 2); below the crustal interplate depth events of magnitude up to $\mathrm{M} \approx 7.5$ may occur.

Figure 2 is from Smith and Berryman's [24] seismicity model, in which the seismicity for each region is measured by the usual magnitude-frequency relationship, described in terms of frequency by parameters $\mathrm{a}_{4}$ and $\mathrm{b}$ (defined later), and maximum magnitude $M_{\max }$. In reviewing the seismicity, occurrence rates in our area of interest since the above model was established remain consistent with the $\mathrm{a}_{4}$ and $\mathrm{b}$ values adopted at that time.

The seismicity model assumes that the seismic activity of the magnitude-frequency relationship is uniformly distributed, but we need to check this assumption for individual locations by considering the capabilities of local seismogenic structures, particularly faults. There is no known active faulting in Region A. The known active faults nearest to Auckland are the Pokeno and Waikato faults in Region B. As shown in Figure 3, they run in an east-west direction about 50 kilometres south of Downtown Auckland. These faults have not been subject to palaeoseismicity studies but general geologic evidence suggests that they may be capable of magnitude $M \approx 7$ events with return periods in excess of 10,000 years.

The possibility of an active fault existing in the Hauraki Gulf has been inferred from displaced sediments located $45 \mathrm{~km}$ east of Downtown Auckland [5]. This may be part of a northward extension of the Kerepehi fault (Figure 3 ) which has been identified on land as far north as Kerepehi [6]. The verified landward part of the Kerepehi fault is thought to be capable of a magnitude 6.5-7 event about once every 5000 years [3]. 


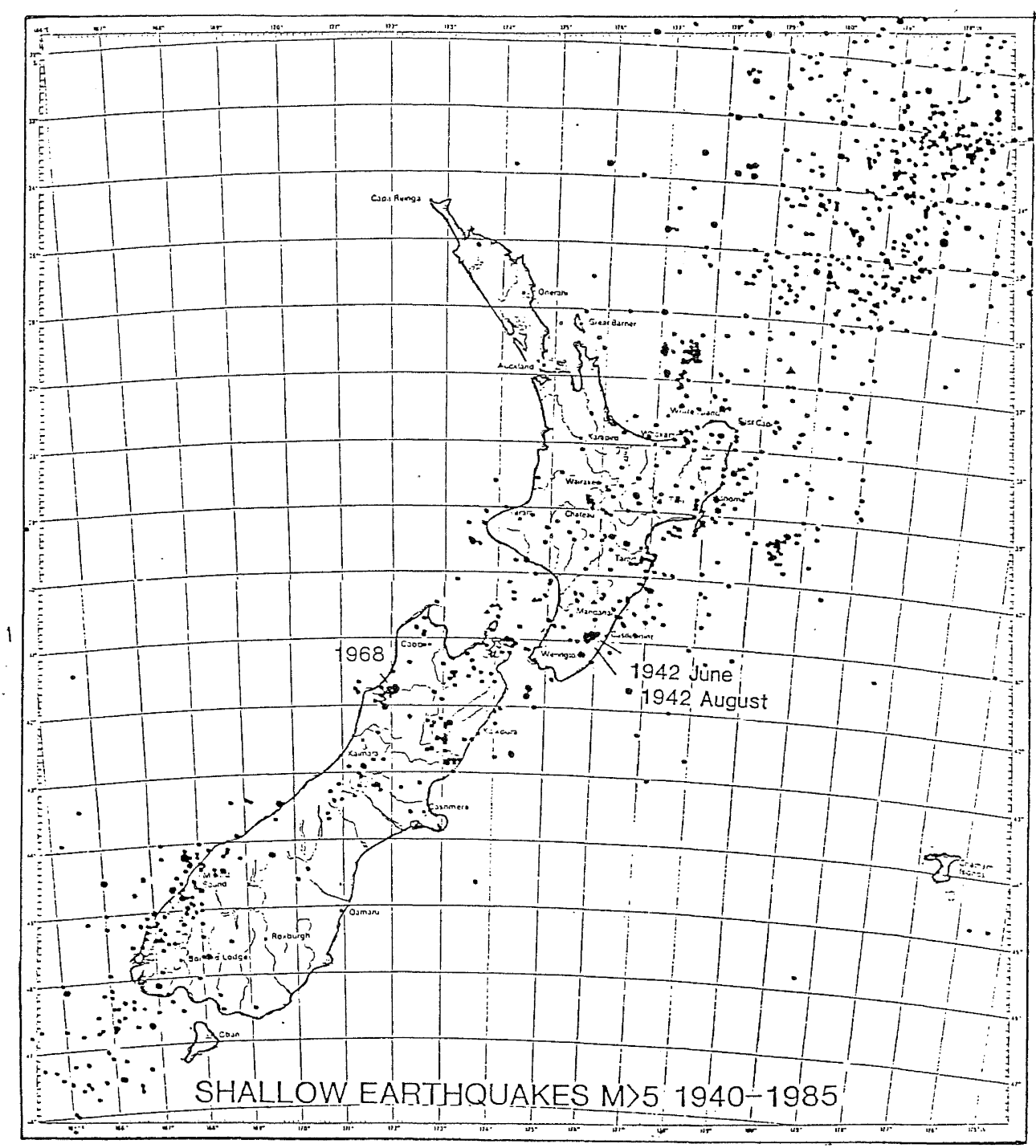

Fig. 1: Shallow earthquakes in New Zealand, $M>5$, 1940-85.

Further faults or possible faults have been mapped off the east coast from North Cape to the Bay of Plenty $[29,30]$, but not enough data exist to evaluate their hazard potential. The eastern and western boundaries of the Hauraki graben, e.g. the Firth of Thames fault, have not moved in the last 500,000 years, and hence are not classified as active (K R Berryman, DSIR, pers comm, 1991).

The currently published $M_{\max }=7.5$ for Region A and 8.0 for Region B [24] are thought to be overly pessimistic, and $\mathrm{M}_{\max }=$ 7.0 and 7.5 respectively are now considered $[3,21]$ to be more realistic values for the purposes of hazard assessment covering a range of recurrence intervals likely to be used in engineering and risk assessment practice.

The second principal factor in hazard assessment is the attenuation of strength of shaking with distance. In a major review of the attenuation of intensity (I) in New Zealand, Dowrick $[10,11]$ has substantially revised the 1970's model of Smith [22]. Both Smith and Dowrick followed the common practice of working with isoseismals rather than taking the approach of Walley [31] and Matuschka [16] who worked with the individual MM reports. The latter approach is attractive because it cuts out the further subjective element introduced in drawing the isoseismals. But isoseismal maps are widely used (e.g. in the study of damage in the Edgecumbe earthquake referred to in Table 6), and hence to be able to model them was the preference of Smith [22] and Dowrick $[10,11]$.

The new attenuation relationships of Dowrick are of the form

$$
I=b_{1}+b_{2} M+b_{3}+b_{4} \log _{10} r
$$

where $b_{1}, b_{2}, b_{3}, b_{4}$ are coefficients which depend on the source mechanism, $M$ is the magnitude and $r$ is the mean slope distance in $\mathrm{km}$ for isoseismal I to the centre of energy release (located at effective depth $h_{c}$ assumed to be at the centroid of the fault rupture surface). Assuming a uniform mixture of reverse, normal and strike-slip source mechanisms we may take approximately 


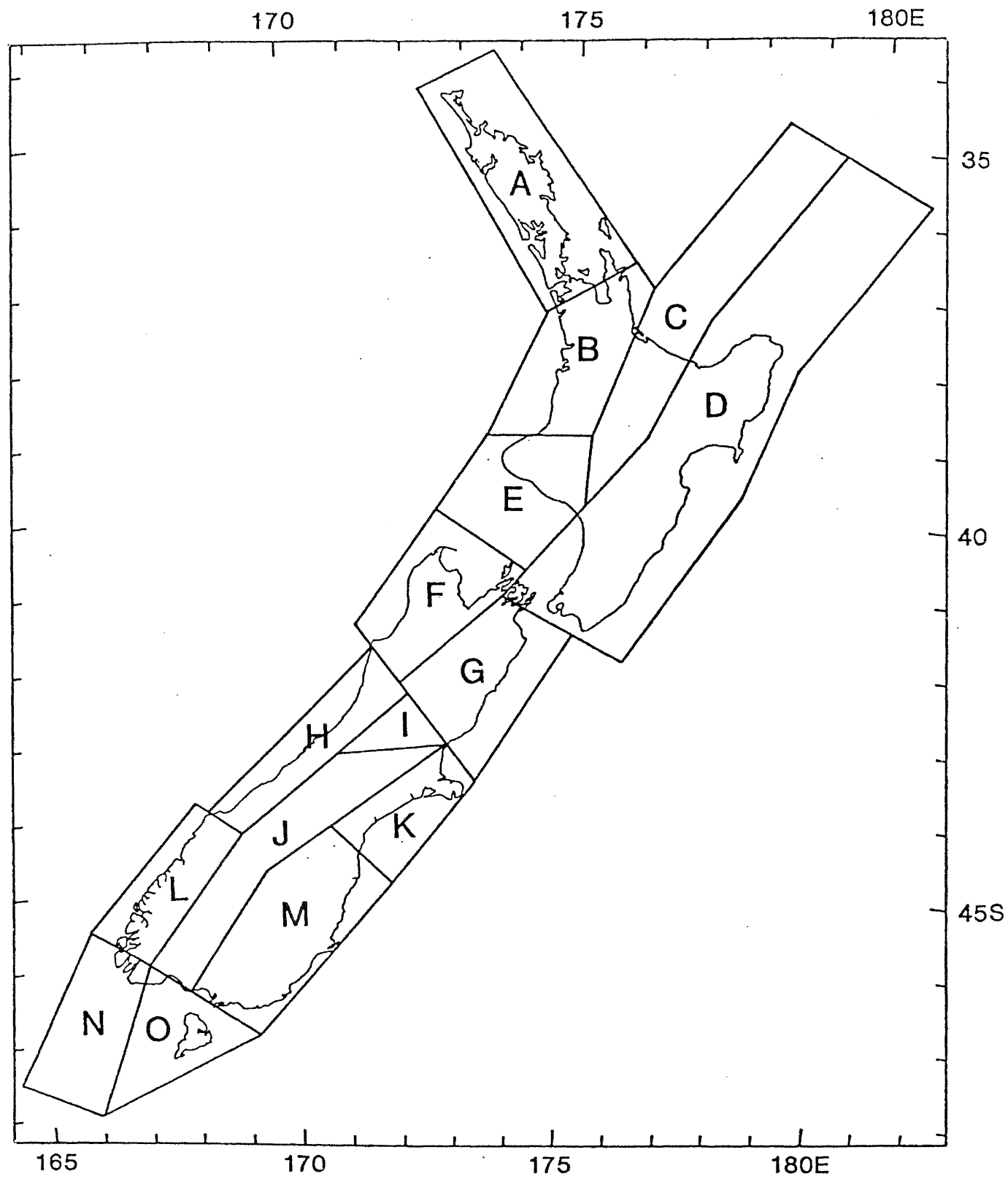

Fig. 2: Regions of the seismicity model of New Zealand from Smith and Berryman [24].

For calculating the return periods of MM intensity in Downtown Auckland a constant value of $h_{c}=6 \mathrm{~km}$ was used (which is the approximate average value for the regions concerned), and a uniform mixture of source mechanisms was assumed. In addition a uniformly distributed seismicity model was adopted, where the annual frequency, per thousand sq $\mathrm{km}$, of earthquakes of magnitude $M$ or greater was given by

$$
\mathrm{N}(\mathrm{M})=\alpha_{4}\left[10^{\mathrm{b}(4-\mathrm{M})}-10^{\mathrm{b}\left(4-\mathrm{M}_{\mathrm{bu}}\right)}\right]
$$

where $a_{4}$ is the annual number of earthquakes of magnitude 4.0 or greater in an area of $1000 \mathrm{sq} \mathrm{km}$, and $\mathrm{b}$ is the exponential decay with magnitude. The values of $a_{4}$ and $b$ adopted were those given in Ref [24], and $M_{\max }=7.0$ and 7.5 for Regions $A$ and $\mathrm{B}$ respectively.
Earlier methods of estimating hazards such as that used by Smith and Berryman [24] summed the contributions of all earthquakes in the distribution, i.e. equation (3), using the values given directly by it, and by the mean attenuation expression, equations (1) and (2). The resulting "median" intensities $I_{o}$ for given return periods take no account of uncertainties in the above expressions for occurrence rate or intensity attenuation. For direct comparison with the results of Smith and Berryman we first present results of the analysis using the above equations, as given in Table 1, without allowing for the effect of uncertainties. It can be seen that the estimates of this study result in greatly reduced hazard levels, except for MM4-5 where the two studies give virtually the same return period. This reduction in estimated hazard results from the combined effects of the revised attenuation expressions [10,11] and the revised $\mathrm{M}_{\max }$ values. The reasons for the differences 


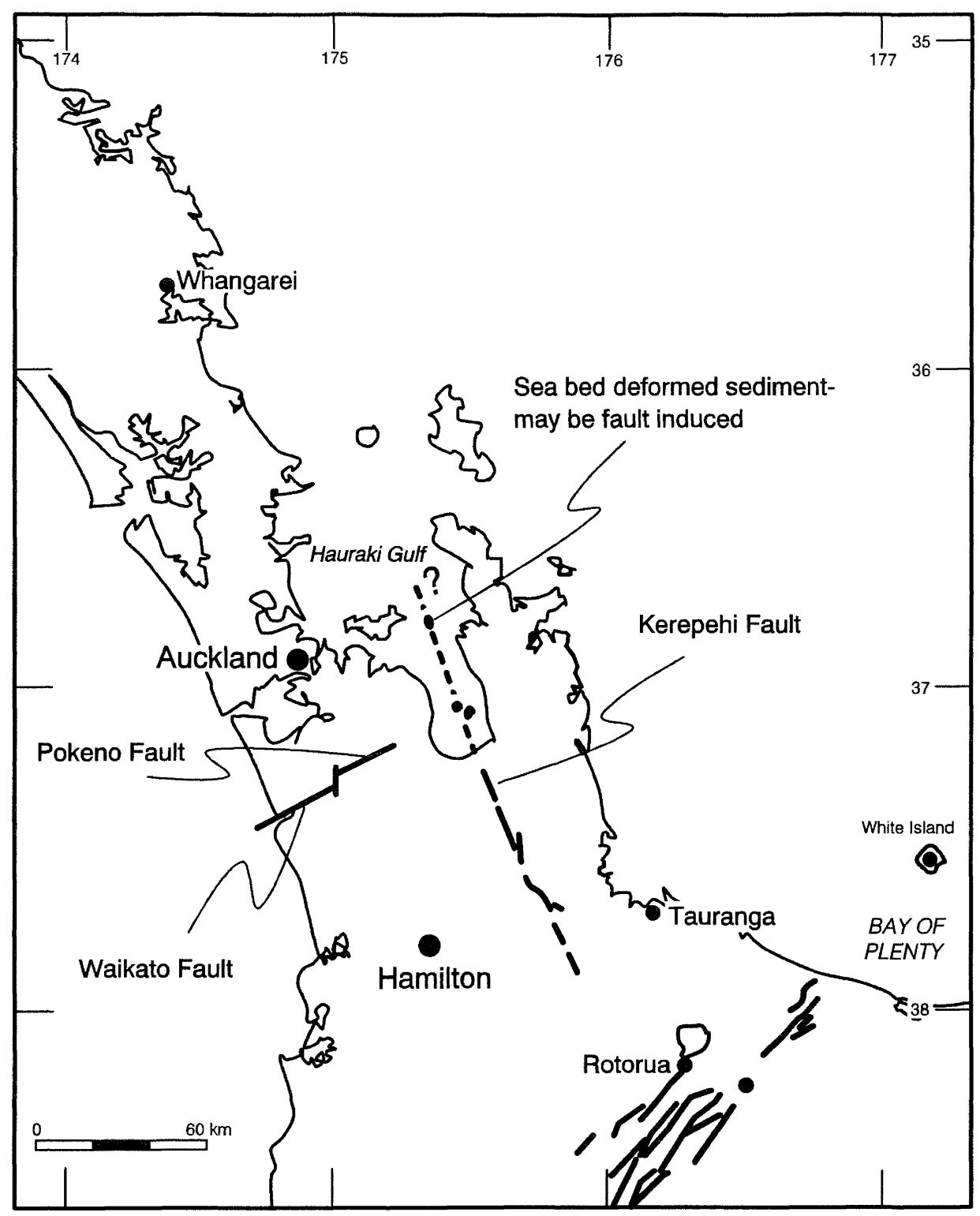

Fig. 3: Map showing known active faults in northern New Zealand.

between the previous and the new attenuation relationships are discussed fully in Refs [10,11] but basically arise from (i) using a revised and consistent magnitude set, (ii) taking account of the depth of the events, and (iii) taking account of course mechanism.

Allowance for uncertainties in effects at a site has been discussed in terms of accelerations by Bender [1] and for New Zealand data by Berrill [2], where it was shown that the estimated hazard increases when uncertainties are taken into account. Similarly the "median" hazard values $I_{o}$ associated with the return periods given in Table 1 , become $\mathrm{I}_{v}$ when uncertainties in equation (1) are considered. It follows that for a given return period,

$$
I_{u}-I_{o}=\frac{\beta \sigma}{2 b_{2}}
$$

where $\beta=\mathrm{b} \log 10=2.3 \mathrm{~b}$,

$b$ is as defined in equation (3),

$\sigma$ is the residual standard deviation of isoseismal $\mathrm{I}$, $b_{2}$ is as defined in equation (1).

Noting that $\sigma \approx 0.5$, and taking $\mathrm{b}=1.2$ as for seismicity regions $\mathrm{A}$ and $\mathrm{B}$ (Fig.2), substituting in equation (4) we find

$$
I_{u}-I_{o}=\frac{2.3 * 1.2 * 0.5}{2 * 1.4}=0.5
$$

The above adjustment is intended to take account of variation in the capability of earthquakes of a given magnitude to cause given intensities at a given distance, as indicated by the residuals in equation (1). However, uncertainties in measuring intensity may also be expected to contribute to the residuals in equation (1). Moreover, the adjustment (equation (4)) is quite sensitive to the assumption of normally distributed errors, and in 
Table 1: Seismic hazard in Downtown Auckland estimated from current model of uniformly distributed seismicity, uncertainties in intensity not allowed for.

\begin{tabular}{|c|c|c|c|c|}
\hline \multirow[b]{2}{*}{$\begin{array}{c}\text { MM } \\
\text { Intensity } \\
\text { Isoseismal } \\
\text { (1) }\end{array}$} & \multicolumn{3}{|c|}{ Estimated Average Return Period (yrs) } & \multirow[b]{2}{*}{$\begin{array}{c}\text { Historical } \\
\text { Average } \\
\text { Return Period } \\
\text { (yrs) } \\
\text { (5) }\end{array}$} \\
\hline & $\begin{array}{c}\text { This Study } \\
\text { (2) }\end{array}$ & $\begin{array}{c}S \& B[24] \\
M_{\max }-0.5 \\
\text { (3) }\end{array}$ & $\begin{array}{c}S \& B \text { [24] } \\
M_{\max } \\
\text { (4) }\end{array}$ & \\
\hline $\begin{array}{l}\geq 4 \\
\geq 5 \\
\geq 6 \\
\geq 7 \\
\geq 8\end{array}$ & $\begin{array}{r}4^{*} \\
18 \\
105 \\
880 \\
8500\end{array}$ & $\begin{array}{r}4 * \\
17 \\
76 \\
420 \\
2400\end{array}$ & $\begin{array}{r}4 * \\
16 \\
62 \\
260 \\
1400\end{array}$ & $\begin{array}{c}c .25 \\
- \\
- \\
- \\
-\end{array}$ \\
\hline
\end{tabular}

*Extrapolated from the calculated points for MM5-9.

particular to the tail-shape of the normal distribution as noted by Bender [1]. Many more data are required before we can make a realistic assessment of the tail-shape. In spite of these misgivings, we take the correction to intensity given by equation (5) at face value, and apply it to increase the hazard estimates in Table 1. This results, for example, in an estimated return period of 2 years for MM4 instead of 4 years as given in columns (2) to (4).

It is noted that the scatter will be larger from attenuation regression analysis of individual intensity observations than when working in terms of isoseismals. This is because of the averaging effect of isoseismals. Thus Matuschka [16] found $\sigma$ to be approximately twice the value used here. However $\sigma=$ 0.5 is the value appropriate for use when modelling isoseismals as has been done here.

\section{ESTIMATED HAZARD VERSUS HISTORICAL RECORD}

The next step is to test the estimates found above against the historical record.

To establish the historical record of the number and rank of isoseismals which have encompassed Downtown Auckland, the first step was to examine the New Zealand Seismological Observatory's listings and isoseismal maps and the catalogues of Eiby, e.g. [13]. Since 1843 earthquakes have resulted in isoseismals MM4-5 occurring (arguably) 5 or 6 times (in 1843?, $1855,1868,1914,1929,1972$ ), MM5-6 has not been observed, MM6-7 has occurred once only (in 1891), and MM7 or greater has not occurred. This means that we have a historical return period for MM4 only; its value of 25 years is given in Table 1 , where it is seen to be about an order of magnitude larger than the value of 2 years given above. While the historical record may be incomplete for this intensity it is unlikely to be out by more than a factor of two or three. (Note that as we are working in terms of isoseismals, the above intensity observations are all in terms of isoseismals not individual local observations of intensity).

In order to compare the estimated hazard with the historical record, it is convenient to consider the number of occurrences of a range of intensities during the historical period 1840-1990, i.e. over the past 150 years. As shown in Table 2 the number of occurrences predicted by the model considerably exceeds the observed number of occurrences for each of MM4, MM5 and MM6 (compare columns 2 and 4).

If we assume that the attenuation expression is not significantly overestimating intensity, then seismicity parameter $\mathrm{a}_{4}$ in equation (3) is obviously much higher than the past 150 years of felt intensity data would indicate.

Assuming that earthquakes occur as a Poisson process and that the observed numbers of occurrences in the last 150 years are not statistically more rare than a 1 in 20 event, then the expected mean numbers of occurrences over a larger time interval satisfy the inequalities given in column 3 of Table 2 . Column (3) gives the range within which the mean of the Poisson distribution must lie for the 5th percentile to be not greater than the observed value (column 4). From a comparison of columns (2) and (3) we conclude that the assumed constant seismicity model is not consistent with the historical intensity record, the assumed seismicity rates being too high.

It is also noted that in Whangarei (135 km north of Auckland) the historical frequency of occurrence of intensity is even less than in Auckland.

An examination of the seismicity data used in deriving $a_{4}$ for Regions A and B in the present seismicity model [24] shows that $\mathrm{a}_{4}$ for Region $\mathrm{A}$ is far from robust and a substantially reduced value could also be justified. Region $A$ is the dominant contributor to hazard in Downtown Auckland. Similarly $\mathrm{a}_{4}$ for Region B, particularly the part of it nearest to Auckland, could also be reduced based on the palaeoseismicity [3] as well as the historical data. The part of Region B nearest to Auckland has a much smaller historical seismicity than the "observed" value [24] for Region B as a whole which is dominated by its more seismically active southern part.

As a cautious step towards correcting the seismicity model we could reduce the value of the parameter $a_{4}$ in equation (3) to conform to the MM5 value in column (3) of Table 2 . This would mean reducing $a_{4}$ to say 0.25 times the present values. Applying this factor and equation (5) to the results in Table 1, we obtain the intensity versus return period data as in Table 3 and Figure 4. 
Table 2: Seismic hazard in Downtown Auckland estimated from uniformly distributed seismicity, allowing for uncertainties in intensity.

\begin{tabular}{|c|c|c|c|}
\hline \multirow[b]{2}{*}{$\begin{array}{l}\text { MM Intensity } \\
\text { Isoseismal }\end{array}$} & \multicolumn{2}{|c|}{ Estimated mean number of events in $150 \mathrm{yrs}$} & \multirow[b]{2}{*}{$\begin{array}{c}\text { Observed number of } \\
\text { events in last } \\
150 \text { years } \\
(1840-1990)\end{array}$} \\
\hline & $\begin{array}{l}\text { Model as per } \\
\text { equations } \\
\text { (2) and (3) }\end{array}$ & $\begin{array}{l}\text { Expected number } \\
\text { if observed } \\
\text { numbers are not } \\
\text { more rare than } 1 \\
\text { in } 20\end{array}$ & \\
\hline (1) & (2) & (3) & (4) \\
\hline$\geq 4$ & 75 & $<12$ & 6 or 7 \\
\hline$\geq 5$ & 19 & $<5$ & 1 \\
\hline$\geq 6$ & 4 & & 1 \\
\hline$\geq 7$ & $(0.5)$ & & 0 \\
\hline
\end{tabular}

Table 3: Seismic hazard in Downtown Auckland estimated from reduced model of uniformly distributed seismicity, allowing for uncertainties in intensity.

\begin{tabular}{||c|c|c|c|c||}
\hline \multirow{2}{*}{$\begin{array}{c}\text { MM Intensity } \\
\text { Isoseismal }\end{array}$} & \multicolumn{2}{|c|}{$\begin{array}{c}\text { Average return periods } \\
\text { (yrs) }\end{array}$} & \multicolumn{2}{c||}{ Number of events in 150 years } \\
\cline { 2 - 5 } & Estimated & Observed & Estimated & Observed \\
\hline$\geq 4$ & $8^{*}$ & c.25 & 11 & 6 or 7 \\
\hline$\geq 5$ & 34 & - & 4 & 1 \\
\hline$\geq 6$ & 176 & - & 1 & 1 \\
\hline$\geq 7$ & 1200 & - & & 0 \\
\hline$\geq 8$ & 10000 & - & & 0 \\
\hline
\end{tabular}

* Extrapolated from calculated points for MM5-9.

\section{HAZARD FROM SPECIFIC SOURCES}

In addition to hazard from uniformly distributed sources, as discussed above, we should also consider specific sources, i.e. active faults, the nearest of which to Auckland have been noted earlier. The mean intensities likely to be caused by these faults in Downtown Auckland are given in Table 4.

As the effect on Auckland of large distant events is of interest, also given in Table 4 is an estimate of the mean intensity in Auckland from the largest events likely to occur in Region D (Fig.2), namely subduction zone events of magnitude 8-8.5. This intensity is only MM6 and as such is probably an overestimate (by about one MM step) as it does not take into account the probable higher inelastic attenuation rate as seismic waves cross the Central Volcanic Region (Region C) noted elsewhere $[10,19]$. The high attenuation material extends to considerable depth [19], so that it is unlikely that focusing of energy can occur by waves reflecting off the mantle, as is thought to have happened in San Francisco during the 1989 Loma Prieta earthquake. The largest historical event from this source was the $\mathbf{M}=7.81931$ Hawkes Bay earthquake located c. $330 \mathrm{~km}$ from Auckland where it produced an intensity of only
c.MM2. New Zealand's largest historical earthquake the 1855 Wairarapa earthquake of $M \approx 8.3[10]$ was centred c. $480 \mathrm{~km}$ from Auckland and produced intensities there of MM4. For comparison the $\mathrm{M}=8.11985$ Michoacan earthquake was centred about $400 \mathrm{~km}$ from Mexico City where it caused very strong long-period resonances in the soft lake bed clays.

The hazard data for specific sources quoted on Table 4 are consistent with those estimated from the uniformly distributed seismicity model (Table 3), as illustrated in Figure 4.

\section{SEISMIC HAZARD AND THE LOADINGS CODE}

In New Zealand the design loadings for normal use buildings have long been based on the strengths of shaking of average ground at an average return period of 150 years. In the 1965 code [25] (which underpins the current code [27], the loadings for Seismic Zone C (which includes Auckland and Northland) were deemed to correspond to MM71/2 [clause 9.9 of Ref 26]. Because of lack of data in 1965, this was a subjective decision based on parallels with zoning practice in the USA at that time. From the data given in Tables 1 and 3 and Figure 4, it can be seen that for a return period of 150 years the expected intensity 


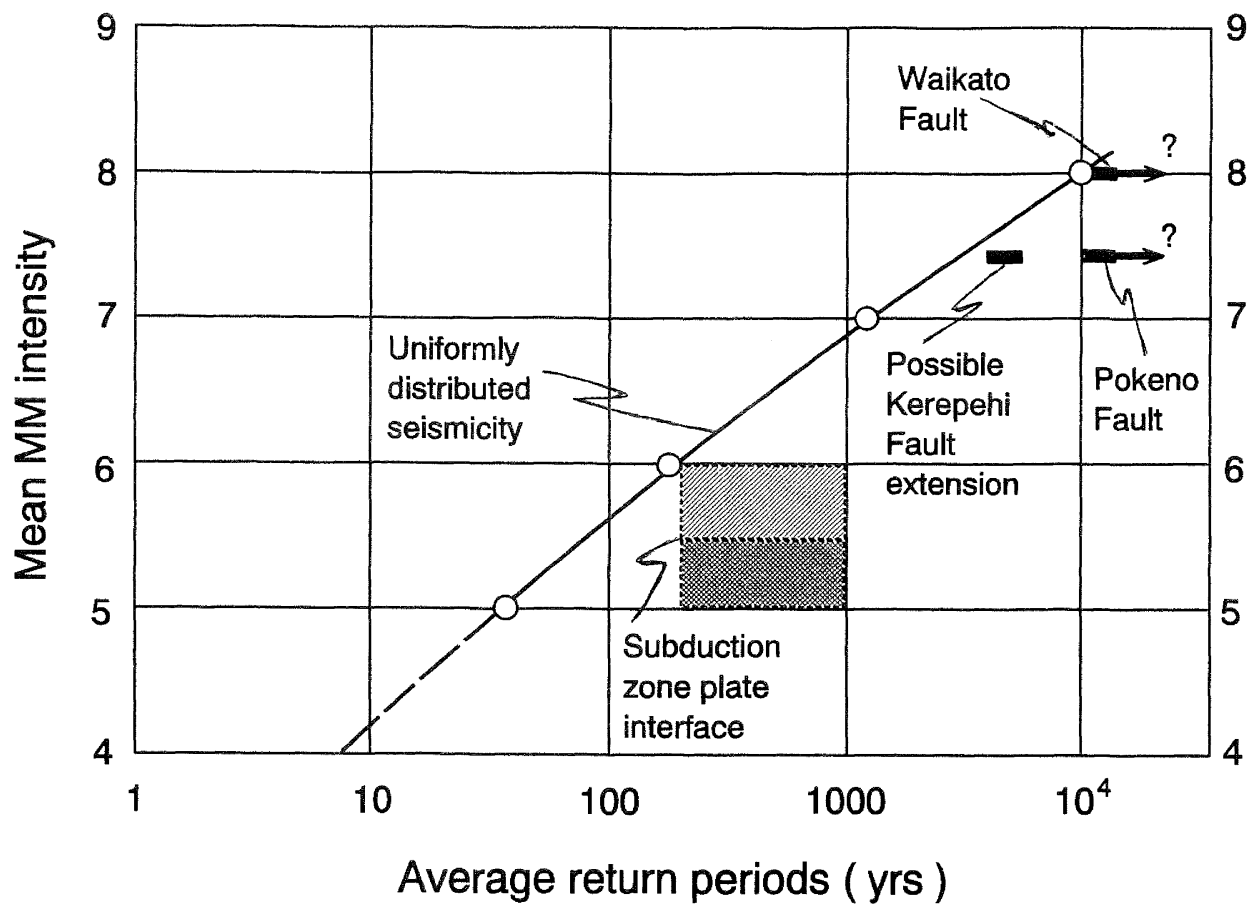

Fig. 4: Seismic hazard in Downtown Auckland estimated in this study. Results from uniformly distributed seismicity model compared with those from specific sources. The subduction Zone contribution is more likely to be in the more heavily shaded area.

Table 4: Seismic Hazard in Downtown Auckland Estimated from Specific Sources.

\begin{tabular}{|l|c|c|c|c||}
\hline \multicolumn{1}{|c|}{ Source } & $\begin{array}{c}\text { Magnitude } \\
\text { Capability }\end{array}$ & $\begin{array}{c}\text { Distance } \\
(\mathbf{k m})\end{array}$ & $\begin{array}{c}\text { Mean } \\
\text { recurrence } \\
\text { Interval } \\
(\mathrm{yrs})\end{array}$ & $\begin{array}{c}\text { Mean MMI } \\
\text { Isoseismal* }\end{array}$ \\
\hline Waikato Fault & $\mathrm{c.7-7.5}$ & 55 & $\mathrm{c.10,000+}$ & 8 \\
\hline Pokeno Fault & $\mathrm{c.7}$ & 48 & $\mathrm{c.10,000+}$ & $7 \frac{1}{2}$ \\
\hline $\begin{array}{l}\text { Kerepehi Fault } \\
\text { possible extension }\end{array}$ & $6-7$ & 45 & $\mathrm{c.5,000}$ & $7 \frac{1}{2}$ \\
\hline $\begin{array}{l}\text { Subduction Zone } \\
\text { Interplate events } \\
\text { (nearest segment) }\end{array}$ & $8-8.5$ & $\mathrm{c.300}$ & $\mathrm{c.200-1000**}$ & $6 \rightarrow 5^{* * *}$ \\
\hline
\end{tabular}

Notes:* Circular isoseismals assumed.

** Obtained from tectonic strain dissipation estimates.

*** See text.

in Auckland lies between MM6 and MM6.7 as estimated respectively in this and previous studies. North of Auckland seismic hazard estimated from the model reduces with distance from the more active Region B (Fig.2). The historical record supports a low level of seismicity, there being only one known land based earthquake of any significance in Northland, i.e. the $\mathrm{M}=5.01963$ Peria event with a strongest isoseismal of MM7 [14]. Thus it is clear that the intended code provisions for our area of interest exceed the estimated hazard by at least one unit of the MM scale. This contrasts with Oamaru in the South Island portion of Zone $\mathrm{C}$ for which the code design intensity of MM71/2 corresponds closely to the hazard estimated by Smith and Berryman [24]. Similarly, the code design intensity of MM8 $1 / 2$ for Zone A closely matches the 150 year hazard level of Ref [24]. Considering the subjective manner of assigning the intensity levels to the zones in 1965, these close correlations may be considered either as good judgement or as somewhat fortuitous! 


\section{DESIGN IMPLICATIONS OF THE HAZARD}

The seismic hazard in Auckland and Northland is so low that we would benefit by carefully reviewing what design measures are appropriate in this region. The standard approach to earthquake resistant design of normal use structures is to achieve two goals with one set of earthquake loads, namely:

1) Accept modest damage levels in "moderate" strength of shaking (i.e. 150 year return period hazard).

2) Provide reserve strength to prevent collapse in "severe" shaking (hazard level not specified explicitly).

In the above examination of the seismic hazard model it was estimated that the 150 year return period mean intensity is c.MM6 for Downtown Auckland (Fig.4), and the estimated intensity will reduce with distance further north. In the definition of MM6 in the Modified Mercalli intensity scale, the only effect on buildings is as follows: "Slight damage to Masonry D (i.e. weak materials such as mud brick and rammed earth; poor mortar; low standards of workmanship)". Clearly there is no need to "design" structures against MM6 shaking, although maintaining some nominal construction and detailing standards would be deemed appropriate.

The 150 year return period intensity of MM6 for Auckland and Northland is significantly less than the intensity of MM71/2 which underlies the current code loadings for Zone $\mathrm{C}$ discussed earlier. For comparison we should note that in the USA the second lowest code zone (Zone 1) was originally considered to correspond to MM6, as stated in earlier editions of the $\mathrm{UBC}[15]$.

\section{Providing Reserve Strength for More Extreme Events}

For most structures in New Zealand there is no requirement to check designs against collapse in extreme events (e.g. the Maximum Credible Earthquake (MCE) concept used for large dams or nuclear reactors). The code provisions for the "150 year" loading, ductility and control of undesirable collapse mechanisms (capacity design) are deemed to provide sufficient reserve strength to postpone collapse in more extreme shaking.

However, in low seismicity areas such as Auckland/Northland, if no specific design is required for the usual design probability level (i.e. the 150 year return period hazard), the design/construction requirements for controlling collapse in more extreme events need to be examined in their own right, at least at the code formulation stage. The appropriate return period for this design level is a question of acceptable risk. For normal-use structures return periods of 500-1000 years are sometimes used, while for major structures like large dams and nuclear reactors the figure is often 10,000 years.
In at least some regions of low seismicity, it appears that the ratio

\section{Return period for extreme design (MCE) \\ Return period for normal design}

is significantly greater than in high seismic risk regions. For example expression (6) for low risk regions is typically in the range $5000 / 500=10$, to that for Auckland of say $10000 / 150=$ 66. In contrast for the high risk region of Wellington, expression (6) is only $550 / 150=3.3$. this has been recognised as a problem for low seismicity areas of the USA [20] (eg, their Zone 1), and for the UK for which an extreme event return period of c. 2000 years has been suggested [4] arising from a reliability analysis. It would appear to be appropriate to carry out some reliability and cost-benefit studies, taking into account both wind and earthquake loads, to assist us in choosing an acceptable extreme hazard level for Auckland/Northland. Assuming 3000 years for the purposes of this discussion, we find from this study's results in Figure 4, that a return period of 3000 years corresponds to a mean intensity of MM71/2 in Downtown Auckland. (This means the old normal design level of MM7 $1 \frac{1}{2}$ now appears to be appropriate for the extreme design level.).

By comparing the definitions of MM7 and MM8 on the MM scale, structural damage responses at MM71/2 are approximately as given in Table 5 .

The MM71/2 damage levels implied by the description in Table 5 , may be quantified by the mean damage ratio:

$$
\mathrm{D}_{\mathrm{rm}}=\frac{\sum_{\mathrm{i}=1}^{\mathrm{n}}\left[\mathrm{Dr} \mathrm{r}_{\mathrm{i}}\right]}{\mathrm{N}}
$$

$$
\text { where } \operatorname{Dr}_{\mathrm{i}}=\frac{\sum \text { cost of Damage to Building } \mathrm{i}}{\sum \text { Replacement Value of Building } \mathrm{i}}
$$

and $\mathrm{n}$ is the number of damaged buildings and $\mathrm{N}$ is the total number of buildings (damaged and undamaged) between the MM7 and MM8 isoseismals.

After the 1987 Edgecumbe earthquake, damage ratios were evaluated for various classes of property as function of intensity $[7,8,9]$. $\quad D_{r m}$ was evaluated for property between each isoseismal, so those found for the MM7 zone (i.e. between MM7 and MM8) correspond to the average damage level for MM71/2. The values of $D_{r m}$ for houses and commercial buildings were very small as shown in Table 6 .

Table 5: $M M^{1} 7^{1 / 2}$ structural responses.

\begin{tabular}{||ll||}
\hline \hline Masonry C moderately damaged & (Not designed or reinforced against lateral forces) \\
\hline Masonry B virtually undamaged & (Reinforced, but not designed in detail against lateral forces) \\
\hline Unbraced parapets and architectural ornaments fall \\
\hline A few brick veneers cracked \\
\hline A few frame houses not secured to foundation may move \\
\hline Unreinforced domestic chimneys broken \\
\hline A few (older) vertical cantilever structures damaged \\
\hline \hline
\end{tabular}


Table 6: Mean damage ratios for buildings located between the MM7 and MM8 isoseismal in the $1987 \mathrm{Edgecumbe}$ earthquake.

\begin{tabular}{|c|c|}
\hline Building Type & $\mathbf{D}_{\mathrm{rm}}$ \\
\hline \hline Houses (all ages) & 0.004 \\
\hline Commercial/Industrial Buildings & \\
Built pre 136 (pre Eq code) & 0.0059 \\
$1936-1964$ & 0.0020 \\
$1965-1974$ & 0.0024 \\
$1975-1986$ & 0.0024 \\
\hline
\end{tabular}

The distribution of damage levels about the mean is shown for houses in Figure 5, which shows that 85 percent of houses were undamaged and only a very few suffered high damage. No houses actually collapsed in the MM7 zone. Commercial and industrial buildings similarly suffered no collapses in this intensity zone, the most heavily damaged being a pre-earthquake code (1927) concrete building which had $D_{r}=0.34$.

The earthquake risk control situation in Auckland/Northland is such that it demands inverting the high seismic risk zone procedure (of designing explicitly for 150 year shaking and implicitly for extreme events), and instead we should design "explicitly" for the extreme events. But as the extreme event is only about $\mathrm{MM} 71 / 2$, and we are only designing against collapse, what kind of design procedure should this be?
For normal use structures, two alternative approaches might be considered:

(i) Nominal horizontal earthquake load analysis, combined with simplified earthquake resistant detailing to suppress undesirable failure mechanisms; or

(ii)Simplified earthquake resistant detailing to suppress undesirable failure mechanisms and to provide minimal horizontal strength, but without earthquake load analysis.

\section{Empirical distribution of damage ratio for buildings}

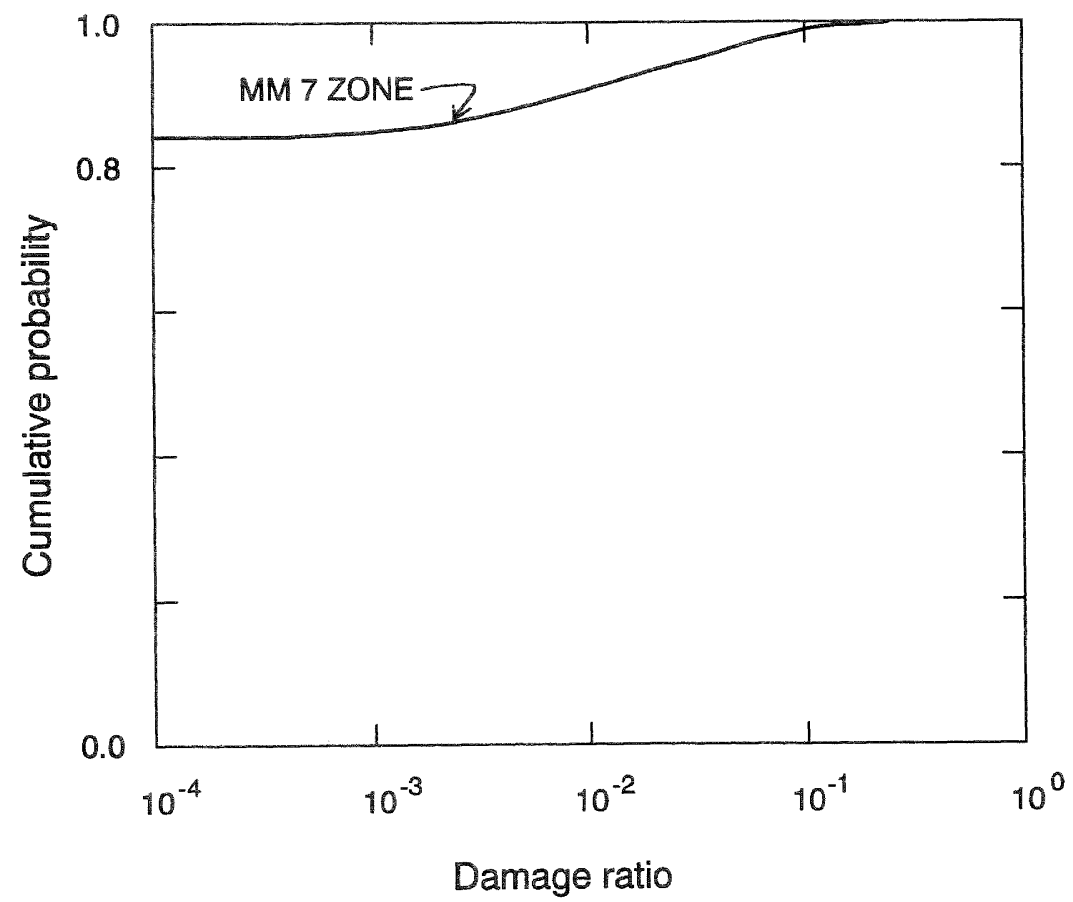

Fig. 5: Empirical distribution of damage ratios for house buildings including undamaged houses for the MM7 zone (average intensity $=\mathrm{MM} \mathrm{71/2}$ ) in the 1987 Edgecumbe earthquake. 


\section{Microzoning}

The above discussion relates to mean intensity levels in a given locality, which is the present standard approach of the codes. It should be noted that the mean intensities in New Zealand are biased toward softer ground conditions because most of our urban areas are on such sites. Another procedural layer in hazard assessment, currently not codified, is that of microzone allowances for effects of local soil conditions. Various New Zealand studies of this subject have been carried out [18], including regional microzoning studies in the greater Wellington area and also Christchurch. Such work should eventually be developed to a design procedure for many of our urban areas, and could lead to microzones of greater and lesser hazard than the values discussed above for the area considered in this paper.

\section{CONCLUSIONS}

From the foregoing study the following conclusions may be drawn:

1. The seismic risk in Auckland/Northland is substantially lower than that given by earlier estimates.

2. The seismic risk level is so low that it indicates that much simpler and less onerous earthquake resistant design and construction procedures should replace the complexities of present day code requirements for this area.

3. The new requirements should be based on robustness for simplified collapse control in the extreme event.

4. Existing older unreinforced masonry buildings in the area need no longer be automatically considered as "high earthquake risk buildings", and much cheaper robustness controls may be adopted rather than the upgrading measures that have been deemed appropriate to date. Individual assessment of course remains appropriate.

5. Reliability and cost-benefit studies may help to define appropriate robustness requirements for different heights and classes of structure.

\section{ACKNOWLEDGEMENTS}

The author wishes to thank his colleagues D.A.Rhoades for assistance on some statistical issues and K.R.Berryman and G.H.McVerry for their constructive in-house reviews of this paper. The helpful comments of an unknown reviewer are also gratefully acknowledged.

\section{REFERENCES}

1. Bender, B. 1984. Incorporating acceleration variability into seismic hazard analysis. Bulletin of the Seismological Society of America 74: 1451-1462.

2. Berrill, J.B. 1985. Seismic hazard analysis and design loads. Bulletin New Zealand National Society for Earthquake Engineering, 18: 139-150.

3. Berryman, K.R. 1991. DSIR, Lower Hutt, Pers. comm.

4. Booth, E.D. and Baker, M.J. 1990. Code provisions for engineered building structures in areas of low seismicity. Proc. Ninth European Conference on Earthquake Engineering, Moscow, 1: 269-278.
5. Carter, L. 1991. DSIR, Wellington, Pers. comm.

6. De Lange, P.J. and Lowe, D.J. 1990. History of vertical displacement of Kerepehi fault at Kopouatai: Bog, Hauraki lowlands, New Zealand, since c. 10,700 years ago. NZ Jnl of Geology and Geophysics, 30: 277-283.

7. Dowrick, D.J. and Rhoades, D.A. 1990. Damage ratios for domestic buildings in the 1987 Edgecumbe earthquake. Bulletin New Zealand National Society for Earthquake Engineering, 23(1): 137-149.

8. Dowrick, D.J. 1991. Damage costs for houses and farms as a function of intensity in the 1987 Edgecumbe earthquake. Earthquake Engineering and Structural Dynamics, 20: 455-479.

9. Dowrick, D.J., and Rhoades,D.A. Damage costs for commercial and industrial property as a function of intensity in the 1987 Edgecumbe earthquake. Submitted to Earthquake Engineering and Structural Dynamics, May 1992.

10. Dowrick, D.J. 1991. A revision of attenuation relationships for Modified Mercalli Intensity in New Zealand earthquakes. Bulletin New Zealand Natl.Soc. for Earthq. Eng., 24: 210-224.

11. Dowrick, D.J. 1992. "Attenuation of Modified Mercalli intensity in New Zealand. Earthquake Engineering and Structural Dynamics, 21: 181-196.

12. Eiby, G.A. 1955. The seismicity of Auckland City and Northland. New Zealand Jnl of Science and Technology $\mathrm{B}(36): 488-494$.

13. Eiby, G.A. 1968. A descriptive catalogue of New Zealand earthquakes, Part 1 - Shocks felt before the end of 1845 . NZ Jnl of Geology and Geophysics 11: 16-40.

14. Eiby, G.A. 1964. Earthquakes in Northland. New Zealand Engineering 19: 125-165.

15. International Conference of Building Officials, 1979. Uniform Building Code. Whittier, California.

16. Matuschka, T. 1980. Assessment of seismic hazard in New Zealand. Report No. 222, Department of Civil Engineering, University of Auckland.

17. Matuschka,T., Berryman,K.R., O'Leary, A.J., McVerry, G.H., Mulholland, W.M., and Skinner, R.I. 1985. New Zealand seismic hazard analysis. Bulletin NZ National Soc. for Earthq. Engineering 18(4): 313-322.

18. McVerry, G.H. and Sritharan, S. 1991. Earthquake site response effects demonstrated by New Zealand strongmotion records. Proc.Pacific Conf. on Earthquake Engineering, Auckland, November, Vol.3: 205-216.

19. Mooney, H.M. 1970. Upper mantle inhomogeneity beneath New Zealand: seismic evidence. Jnl Geophysical Research 75: 285-309.

20. Nordenson, G. 1989. Wind versus seismic design. In: Earthquake hazards and the design of constructed facilities in the Eastern United States. New York Academy of Sciences, New York. 
21. Reyners, M.E. 1990. DSIR, Wellington, Pers.comm.

22. Smith, W.D. 1978a. Spatial distribution of felt intensities for New Zealand earthquakes. NZ Jnl of Geology and Geophysics 21: 293-311.

23. Smith, W.D. 1978b. Earthquake risk in New Zealand : statistical estimates. NZ JnI of Geology and Geophysics 21: 313-327.

24. Smith, W.D. and Berryman, K.R. 1986. "Earthquake hazard in New Zealand: inferences from seismology and geology. Royal Society of New Zealand, Bulletin 24: 223243.

25. New Zealand Standards Institute. 1965. New Zealand Standard Model Building Bylaw, Chapter 8, Basic design loads. NZSS 1900 . Wellington.

26. New Zealand Standards Institute. 1965. Commentary of Chapter 8 of NZSS 1900. MP12. Wellington.

27. Standards Association of New Zealand. 1984. Code of practice for general structural design and design loadings for buildings. NZS 4203. Wellington.

28. Standards Association of New Zealand. 1991. General structural design and design loadings for buildings. Draft New Zealand Standard. DZ4203. Wellington.

29. Thrasher, G.P. 1986. Basement structure and sediment thickness beneath the continental shelf of the Hauraki Gulf and offshore Coromandel region, New Zealand. NZ Jnl Geology and Geophysics 29(1): 41-50.

30. Thrasher, G.P. 1988. Subsurface geology of the continental shelf, Bay of Plenty to the Three Kings Islands, New Zealand. NZ Geological Survey. Report G133. Lower Hutt.

31. Walley, P. 1976. The estimation of earthquake risk in New Zealand. Technical Report No.49, Applied Mathematics Division, Department of Scientific and Industrial Research, Wellington. 